\title{
Clinical Applications of Personalized Medicine: A New Paradigm and Challenge
}

\author{
Mariantonia Di Sanzo ${ }^{1}$, Vittorio Fineschi ${ }^{1,2}$, Marina Borro ${ }^{3}$, Raffaele La Russa ${ }^{1,4, *}$, \\ Alessandro Santurro ${ }^{1}$, Matteo Scopetti ${ }^{1}$, Maurizio Simmaco ${ }^{3}$ and Paola Frati ${ }^{1,4}$ \\ ${ }^{I}$ Department of Anatomical, Histological, Forensic and Orthopaedic Sciences (SAIMLAL), Sapienza University of \\ Rome, Viale Regina Elena 336, 00185 Rome, Italy; ${ }^{2}$ IRCCS Neuromed, Via Atinense 18, 86077 Pozzilli, Italy; \\ ${ }^{3}$ Department of Neurosciences, Mental Health and Sensory Organs (NESMOS), Sapienza University of Rome, Via di \\ Grottarossa 1035, 00189 Rome, Italy; ${ }^{4}$ Malzoni Clinical-Scientific Institute (MaCSI), Via Carmelo Errico 2, $83100 \mathrm{Av}$ - \\ ellino, Italy
}

\begin{tabular}{l} 
A R T I C L E H I S T O R Y \\
\hline Received: July 31,2016 \\
Revised: September 25,2016 \\
Accepted: September 29,2016 \\
DOI: \\
$10.2174 / 13892010186661702241056$ \\
00
\end{tabular}

\begin{abstract}
The personalized medicine is an emergent and rapidly developing method of clinical practice that uses new technologies to provide decisions in regard to the prediction, prevention, diagnosis and treatment of disease. A continuous evolution of technology and the developments in molecular diagnostics and genomic analysis increased the possibility of an even more understanding and interpretation of the human genome and exome, allowing a "personalized" approach to clinical care, so that the concepts of "Systems Medicine" and "System Biology" are actually increasing. The purpose of this study is to evaluate the personalized medicine about its indications and benefits, actual clinical applications and future perspectives as well as its issues and health care implications. A careful review of the scientific literature on this field that highlighted the applicability and usefulness of this new medical approach as well as the fact that personalized medicine strategy is even more increasing in numerous fields of applications.
\end{abstract}

Keywords: Personalized medicine, Genetic tests, Precision medicine, Medicine system, Genomic medicine, Molecular diagnostic, Pharmacogenomics, Healthcare.

\section{INTRODUCTION}

"Personalized medicine" is a generic term, without a clear definition, used in numerous different meanings that often disagree about its real meaning [1]. Therefore, it is necessary to first analyze the explanations on this topic received from the highest positions in Europe and USA.

According to the European Parliamentary Research Service (EPRS 2015), it refers to an "emerging - evolving approach to medicine" that uses scientific insights into the genetic and molecular basis of health and disease brought on by the sequencing of the human genome, to guide decisions in regard to the prediction, prevention, diagnosis and treatment of disease. Therefore, the aim of the Personalized Medicine is generally perceived to be the "right treatment for the right person at the right time" [2].

Similarly, the National Cancer Institute (NIH) underlined the three main purposes of the Personalized Medicine: to

*Address correspondence to this author at the Department of Anatomical, Histological, Forensic and Orthopaedic Sciences, Sapienza University of Rome, Viale Regina Elena 336, 00185 Rome, Italy; Tel: + 3906 49912622; Fax: + 3906 4455335; E-mail: raffaele.larussa@uniroma1.it prevent, to diagnose and to treat disease, using specific information about genes, proteins and environment of each patient [3].

Furthermore, the President's Council of Advisors on Science and Technology - Executive Office of the President of the United States - with a report on September 2008, has specified that the term Personalized Medicine "does not literally mean the creation of drugs or medical devices that are unique to a patient, but rather the ability to classify individuals into subpopulations that differ in their susceptibility to a particular disease or their response to a specific treatment. Preventive or therapeutic interventions can then be concentrated on those who will benefit, sparing expense and side effects for those who will not" [4].

The continue evolution of technology and the developments in molecular diagnostics and genomic analysis increased the possibility of an even more understanding and interpretation of the human genome and exome, allowing a "personalized" approach to clinical care. The medicine has attempted for a long time to reach this objective and the progress in the genomic field promises to facilitate this trial. In fact, the possibility of identifying the individual susceptibil- 
ity to certain diseases and responses to therapy is the necessary step to properly implement the best strategy for disease prevention and care with a treatment that meet the individual needs and characteristics of each patient $[5,6]$.

We currently have different typologies of genetic tests: molecular tests analyze genes and short lengths of DNA; chromosomal tests study the whole chromosomes and long lengths of DNA; biochemical tests study the amount and the activity level of proteins. Moreover, the implementation of whole-exome sequencing - chipper than whole-genome sequencing - that analyzes selectively coding regions, is used to discover rare coding variants and then to identify both common and rare genetic disease. Metabolomics (study of the metabolome: all of metabolites in an organism), pharmacogenomics (interaction between drug and individual genetic make-up), transcriptomics (quantitative study of all genes in an organism) and proteomics (analysis of proteome: the entire collection of proteins in an organism, tissue type or cell) play an even more relevant role in personalizing medicine. All these tests, analyzing human DNA, RNA and proteins, can identify variations, mutations, gene variants, genetic anomalies and metabolic profiles that are associated with certain diseases and that can influence the therapy response. In this way, they can interfere in all of the phases of disease: susceptibility and risk factors, preclinical progression, diagnosis, disease progression and therapy, being able to recognize different types of tests applicable in clinical practice, such as diagnostic testing (to identify a disease and to assist in clinical decision-making), predictive testing (to calculate the likelihood of developing a disease), carrier testing (to understand the likelihood of passing a genetic disease to a child), prenatal testing (to identify disease in a fetus), newborn screening (to determine if a newborn has a disease known to cause problems in health and development), pharmacogenomics testing (to determine the optimal drug therapy and dose given a person's metabolic response) and research testing (to contribute to understanding of underlying cause of disease) [7-9].

This new approach to medicine, based on emerging technologies and sciences, has changed the medical practice and consequently the health care system. The possibility to predict and to intervene before damage, has transformed the reactive health care system, based on the treatment of diseases, in a "prospective health care" system, focused on prevention and treatment of diseases in relationship with a personalized risk. Analyzing scientific literature, it can be shown that the concepts of "Systems Medicine" and "System Biology" are actually increasingly. In fact, the new trend of particular interest is the so-called "P4 systems medicine": Predictive, Preventive, Personalized and Participatory, concept pursued by the oncologist Leroy Hood since 2011 [10]. It gives up the reductionist medicine to embrace a revolutionary holistic approach aimed at healthcare optimization, focusing on the interactions of a biological system and studying the whole life process from the molecular to the social [11].

In the last decades, numerous risk loci for common and rare diseases have been identified and discovered many genetic variants that influence the action of pharmacologic agents. But, with the evolution of these sciences, the drop in the cost of sequencing (especially whole-exome) and the availability of numerous databases, the number of studies and publications on this topic have been increased in the last years. Therefore, it is relevant to recognize the clinical applicability and the healthcare implications of this new biomedical approach as well as its limits, to better understand how to improve its usage in the future [12].

\section{CLINICAL APPLICATIONS AND FUTURE PER- SPECTIVES OF PERSONALIZED MEDICINE}

Nowadays, the personalized medicine strategy is increasing in numerous fields of applications, thus revolutionizing the medical practice. To understand its real impact to clinical practice, firstly it is necessary to dissect the main clinical areas of interest, focusing the attention on the actual findings and usage of each of them and the future perspectives.

\section{ONCOLOGY}

The oncology is the most commonly interested area by the personalized medicine on the basis of the same nature of the cancer. In fact, cancer is a complex disease characterized by the accumulation of mutations occurring in critical genes and resulting in the alteration of molecular paths. The application of genetic tests in oncology involves both healthy and sick persons: the first one, may benefit from screening tests that can identify the risk of developing some disorders; the second one, can be benefitted by the best therapeutic strategy, thanks to the molecular characterization of the cancer that allows new knowledge into the prediction of the disease progression and in response to the treatment for each patient. Hereditary cancers are about $10-15 \%$ of total cancer but many studies of the human genome have allowed to determine the risk of cancer and to discover the prognostic and predictive biomarkers. Furthermore, some genetic variants of genes were discovered that metabolize drugs, allowing to understand the toxicity of specific drugs and the response to therapy [13]. Nowadays, the association between genomic variations with different cancers, such as the BRCA 1 and 2 and PARP genes in breast cancer tumors, ERBB2 receptor in breast adenocarcinoma, BCR/ABL fusion gene in chronic myelogenous leukemia, BRAF (V600E) in melanoma, colorectal and thyroid cancer, is well established. Furthermore, genetic tests provide a number of information about the best therapy allowing a target therapy: examples are the usage of Herceptin in female breast cancer patients with HER-2 expression, the Imatinib that targets the BCL/ABL, the Vemurafenib targeting BRAF in melanoma or the usage of Gleevec to inhibit tyrosine kinase in chronic myleloid leukemias.

Considering that all types of tumor cannot be described in detail in a single article, we have chosen to summarize in Table 1 the variants with greater scientific value found in the literature and recognized by the National Institute for Cancer [14].

Despite numerous studies have been made, the development of new genetic variants is still in progress. The possibility to search within each tumor the actionable/druggable alteration using new technologies opens the way to Personalized Medicine in the field of oncology $[15,16]$. 
Table 1. Targeted therapies approved by the FDA for the treatment of some types of cancer. Several targeted therapies have been approved to treat more than one type of cancer.

\begin{tabular}{|c|c|c|}
\hline Gene & Tumor Type & Targeted Agent \\
\hline HER2 & Breast cancer and gastric cancer & Trastuzumab \\
\hline BRAF & Melanoma, colorectal cancer and thyroid cancer & Vemurafenib \\
\hline BCR-ABL & Chronic myleloid leukemia, GIST and myeloproliferative disorders & Imatinib \\
\hline KDR & Gastric cancer, colorectal cancer and lung cancer & Ramucirumab \\
\hline SMO & Basal cell carcinoma & Vismodegib, Sonidegib \\
\hline $\mathrm{CD} 274$ & Bladder cancer & Atezolizumab \\
\hline VEGF & $\begin{array}{l}\text { Brain cancer, cervical cancer, colorectal cancer, kidney cancer, lung cancer, ovarian epithelial cancer, } \\
\text { fallopian tube cancer and primary peritoneal cancer }\end{array}$ & Bevacizumab \\
\hline MTOR & Brain cancer, breast cancer, kidney cancer and pancreatic cancer & Everolimus \\
\hline HER1/HER2 & Breast cancer & Lapatinib \\
\hline HER2 & Breast cancer & Pertuzumab \\
\hline CDK4/CDK6 & Breast cancer & Palbociclib \\
\hline EGFR & Colorectal cancer, head and neck cancer & Cetuximab \\
\hline EGFR & Colorectal cancer & Panitumumab \\
\hline PDCD1 & Kidney cancer, lung cancer, lymphoma and melanoma & Nivolumab \\
\hline MS4A1 & Leukemia and lymphoma & Rituximab \\
\hline BCR-ABL & Leukemia & Dasatinib \\
\hline CD52 & Leukemia & Alemtuzumab \\
\hline EGFR & Lung cancer & Gefitinib \\
\hline EGFR & Lung cancer and pancreatic cancer & Erlotinib \\
\hline $\mathrm{CD} 38$ & Multiple myeloma & Daratumumab \\
\hline
\end{tabular}

\section{PSYCHIATRY AND "P5 MEDICINE SYSTEM"}

The psychiatric diseases are multifactorial pathologies and already validated the influence of genetic in some of them. Ozomaro et al. pointed out as several studies demonstrated the correlation between genetic alterations and some disorders: schizophrenia is one of the disorders most influenced by genetic with a risk of heritability of 50 to $80 \%$, the genetic risk of the major depressive disorder is estimated in a range of $40-70 \%$, and also the bipolar disorder is highly heritable, with genetic variables estimated for 60 to $85 \%$ of risk [17]. Nevertheless, psychiatric diseases today are diagnosed by symptoms and psychopathological tests with a categorical approach summarized in the criteria from the Diagnostic and Statistical Manual of Mental Disorders (DSM). But a new approach in the field of psychiatric disorders diagnosis was proposed by Bragazzi that suggested to apply omics science in psychiatry. This approach, based on the fact that psychiatric disorders share biological background and environmental exposures, can allow a further evolution of the P4 medicine introducing a new domain: the Psycho-cognitive one. So, it could switch to the new P5 medicine system in which psychological health is seen as an essential aspect of personal well-being [18]. Numerically increasing, the $\mathrm{P}$ is required by many different disciplines, keeping in view the further added value of "Protection (P5)", therefore, invoking the need for the patient to be protected and then a conceptual system to be understood as equity in distribution of resource and free access to personalized medicine.

This new system is obviously extended to the usage of omics in evaluation of treatment response. In fact, Shaunna L. Clark at al. in 2011, and Daniel E. Adkins et al. in 2013, with an analysis made using data from CATIE (Clinical Antipsychotic Trials of Intervention Effectiveness) and STAR*D (Sequenced Treatment Alternatives to Relieve Depression) $[19,20]$, proved the correlation between genotype background and efficacy and effects of the treatment. Therefore, their results highlighted the potential to personalize antipsychotic treatment and the importance of identifying predictors of drug response [21, 22]. In fact, in addiction to numerous studies about the well-known Cytochrome P450, other gene associations have been studied to evaluate the antidepressant treatment response, such as SLC6A4 and FKBP5 involved in glucocorticoid trafficking, HTR2A that encodes a serotonin $2 \mathrm{~A}$ receptor [23], ABCB1 that encodes a p-glycoprotein that affects brain concentrations of some antidepressants [24], CYP2D6*4 polymorphism influencing on 
dose, switching and discontinuation of antidepressants [25]. Moreover, many studies highlighted the correlation between some antipsychotic drugs and adverse reactions [26-29]. All these results are shown in Table 2.

However, many results of these analyses are waiting for a replication in largest samples [30].

These findings suggest that much more can be done in the field of personalized psychiatry to improve both diagnosis method and treatment strategy with a great impact on medical practice and patient well-being. A more precise and effective therapy, can and should be there for the sick person and patients should be involved in decision-making, and be fully informed about the treatment.

\section{NEUROLOGY}

The role of genes has been associated with some neurological diseases, such as, for examples: Duchenne Muscular Dystrophy, a recessive X-linked disease; Alzheimer's Disease, a degenerative brain disease which are not clearly understood because the genes may play an important role in the development of disease (among the numerous genes identified are the APP, the PSEN1, the PSEN2 and the APOE). Parkinson's Disease is a complex neurological disorder that, even if it is not a genetic disease, it has a family history in $15 \%$ of individuals, possibly caused by mutations in LRRK2, PARK2, PARK7, PINK1 or SNCA genes or by alterations in genes not yet identified. Epilepsy, another complex neurological disorder with numerous causes of brain dysfunction where, in majority of the cases, there is an interaction between multiple genes and environmental factors, while in 1$2 \%$ of cases a single gene defect (SCN1A and PCDH7 genes are associated with an increase disease risk) is recognized. These disorders, characterized by a great heterogeneity and variability in susceptibility, causation, clinical profiles and drug response, are an optimal target for the usage of omics sciences and many clinical institutes have already considered the routinely usage of genetic technologies to select the best treatment for a single patient. In fact, being these neurological diseases chronic and irreversible, the opportunity to know the drug response plays a very important role: it could lead to new treatment frameworks with a better effectiveness and reduced side effects and it can completely change the lives of the patients suffering from these diseases. Unfortunately, genomics knowledge in this field is still limited and clinical trials are limited by the lack of DNA data collections, long times and elevated costs $[31,32]$.

\section{CARDIOVASCULAR DISEASES}

Many studies reported that the variation in clinical cardiovascular diseases (CVDs) depend on heritable factors and its risk factors. Examples are a familial predisposition of myocardial infarction, atrial fibrillation, and congestive heart failure. Moderate heritability conditions include coronary artery calcification, blood pressure, total cholesterol, and body mass index. The American Heart Association reviewed genomic epidemiology by three categories of cardiovascular condition: atherosclerosis and myocardial infarction, elevated cholesterol and other lipid disorders, and blood pressure and hypertension. The National Heart, Lung, and Blood Institute of USA summarized possible genetic contributors related to risk of coronary heart disease. Many kinds of genes considered mostly likely to potentially contribute toward an increased risk of coronary heart disease. The main application of clinical genomic in this field is the study about the influence of genes in drug response. Examples of biomarkers and genetic tests used in cardiovascular disease are summarized in Table 3 [33-46].

Recently, different authors studied the applications of pharmacogenomics in the most common antiplatelet (clopidogrel and aspirin) and anticoagulation (warfarin) therapy. They proved as the genetic variants are important determinants of antiplatelet and anticoagulation therapy response and then that the application of pharmacogenetic can provide important information to assist clinicians with prescribing the most personalized and effective antiplatelet and anticoagulation therapy. Thus, a future view is to apply this knowledge for the next-generation antiplatelet (prasugrel and ticagrelor) and anticoagulant (dabigatran) agents on the fact that a genetic susceptibility also is recognized for them [47-49].

A big limitation of the use of personalized medicine in this field is that, despite multiple studies have been performed, the results of literature are discrepant and inconclusive in some instances. This might be due to inadequately powered studies, studying the different drug response phenotypes or patient populations (differences in allele frequencies), problems precisely measuring the phenotype, subtlety of functional effects of polymorphisms, focus on single SNPs instead of haplotypes, and failure to consider the complexity of drug response [50]. For example, response to currently used antiarrhythmic therapies is notoriously variable, with some patients deriving clear cut benefit, such as reduction in episodes of paroxysmal atrial fibrillation, while other derive no benefit or even develop new arrhythmias, such as diLQTS. Some variability in response to antiarrhythmic drug therapy, as in variability in response to many other forms of pharmacologic therapy, can be attributed to variable drug disposition. For example, loss-of-function variants in CYP2D6, encoding a hepatic cytochrome P450 responsible for metabolism of approximately of $25 \%$ of clinically used drug [51]. Therefore, being recognized as the great potential to personalized medicine in this field, more studies are needed to a better understanding and standardization of results.

\section{CHRONIC CONDITIONS, METABOLOMICS PRO- FILE AND PERSONALIZED LIFESTYLE MEDICINE}

It is known that chronic and lifestyle-induced conditions, such as metabolic syndrome, type 2 diabetes, cardiovascular diseases and obesity, are correlated with a high rate of hospitalization. In particular, coronary heart disease and type 2 diabetes (preventable chronic diseases) are leading causes of morbidity and mortality in the United States [52].

Many studies have already demonstrated the impact of genes in Diabetes Mellitus and its risk factors as well as the interactions between genetic make-up and response to diet and dietary changes, both in terms of predisposing to development of obesity, metabolic syndrome and Diabetes Mellitus 2 , and in determining responsiveness to specific dietary changes. 
Table 2. Role of genetic testing in Psychiatry: fields of application and impact on clinical practice.

\begin{tabular}{|c|c|c|}
\hline Genetic Testing & Applications & Impact on Clinical Practice \\
\hline $\mathrm{ABCB} 1$ gene & Antidepressant treatment & Prediction of responsiveness to certain antidepressants \\
\hline CYP2D6 gene & Antidepressant and antipsychotic treatment & $\begin{array}{l}\text { Evaluation of drug metabolism } \\
\text { Assessment of dose requirement }\end{array}$ \\
\hline HTR2A gene & Antidepressant treatment & Prediction of responsiveness to citalopram administration \\
\hline CYP2C9 gene & Antidepressant, antipsychotic and anticonvulsant treatment & Evaluation of drug metabolism \\
\hline CYP2C19 gene & Antidepressant, antipsychotic and anticonvulsant treatment & Evaluation of drug metabolism \\
\hline HLA-A gene & Anticonvulsant treatment & $\begin{array}{c}\text { Evaluation of risk of carbamazepine hypersensitivity } \\
\text { syndrome }\end{array}$ \\
\hline $\mathrm{ABCC} 2$ gene & Anticonvulsant treatment & $\begin{array}{l}\text { Assessment of the probability of neurological adverse drug } \\
\text { reactions from taking carbamazepine }\end{array}$ \\
\hline CREB1 gene & Antidepressant treatment & $\begin{array}{l}\text { Prediction of treatment related suicidal ideation with } \\
\text { citalopram }\end{array}$ \\
\hline $\begin{array}{l}\text { Kainate type ionotropic } \\
\text { glutamate receptor } 4 \\
\text { (GRIK4) gene }\end{array}$ & Antidepressant treatment & Prediction of responsiveness to citalopram \\
\hline RGS2 gene & Antipsychotic treatment & Prediction of risk of antipsychotic induced parkinsonism \\
\hline PON1 gene & Antipsychotic treatment & $\begin{array}{l}\begin{array}{c}\text { Assessment of the probability of weight gain from taking } \\
\text { risperidone }\end{array}\end{array}$ \\
\hline NPY1R gene & Antipsychotic treatment & $\begin{array}{c}\text { Assessment of the probability of weight gain from taking } \\
\text { risperidone }\end{array}$ \\
\hline $\begin{array}{l}\text { Glutamate decarboxylase } \\
\text { like } 1 \text { (GADL1) gene }\end{array}$ & Affective disorders treatment & Prediction of responsiveness to lithium \\
\hline
\end{tabular}

Table 3. Biomarkers and genetic tests used in cardiovascular disease.

\begin{tabular}{|c|c|c|}
\hline Genetic Testing & Application & Impact on Clinical Practice \\
\hline $\begin{array}{l}\text { Natriuretic peptide precursor A (NPPA) } \\
\text { gene }\end{array}$ & Antihypertensive therapy & $\begin{array}{l}\text { Prediction of responsiveness to diuretic versus calcium channel blocker } \\
\text { treatment }\end{array}$ \\
\hline CACNA1D gene & Antihypertensive therapy & Prediction of responsiveness to certain calcium channel blockers \\
\hline LPA gene & Antiplatelet treatment & $\begin{array}{l}\text { Prediction of cardiovascular risk and benefits from acetylsalicylic acid ad- } \\
\text { ministration }\end{array}$ \\
\hline Integrin beta 3 precursor (ITGB3) gene & Antiplatelet treatment & $\begin{array}{l}\text { Enhanced thrombin formation and impaired antithrombotic action of acetyl- } \\
\text { salicylic acid }\end{array}$ \\
\hline KIF6 gene & Lipid lowering treatment & Prediction of responsiveness to statin treatment \\
\hline $\begin{array}{l}\text { Beta } 1 \text { adrenergic receptor (ADRB1) } \\
\text { gene }\end{array}$ & Antihypertensive therapy & Prediction of antihypertensive response to metoprolol \\
\hline CYP2D6 gene & Antihypertensive therapy & Identification of poor metabolizers that are at increased risk of bradycardia \\
\hline CYP2C19 gene & Antiplatelet treatment & Characterization of responsiveness to clopidogrel administration \\
\hline ACE gene & Antihypertensive therapy & Prediction of effectiveness of ramipril administration \\
\hline $\begin{array}{l}\text { Solute carrier organic anion transporter } \\
\text { family member } 1 \mathrm{~B} 1 \text { (SLCO1B1) gene }\end{array}$ & Lipid lowering treatment & Assessment of statin induced myopathy risk \\
\hline
\end{tabular}




\begin{tabular}{|c|c|c|}
\hline Genetic Testing & Application & Impact on Clinical Practice \\
\hline \hline HMGCR gene & Lipid lowering treatment & Prediction of responsiveness to pravastatin administration \\
\hline CYP2C9 gene & Anticoagulant treatment & Evaluation of warfarin metabolism \\
\hline VKORC1 gene & Anticoagulant treatment & $\begin{array}{c}\text { Prediction of warfarin dose requirement } \\
\text { Evaluation of warfarin resistance }\end{array}$ \\
\hline $\begin{array}{c}\text { Familion 5-gene profile } \\
\text { Niemann-Pick CI Like I (NPCILI) } \\
\text { haplotype }\end{array}$ & $\begin{array}{c}\text { Prevention and treatment of } \\
\text { cardiac channelopathies }\end{array}$ & Drug selection in patients with cardiac channelopathies such as LQTS \\
\hline Apolipoprotein A5 (ApoA5) genotype & Lipid lowering treatment & Prediction of benefits from ezetimibe administration \\
\hline
\end{tabular}

But the future for these particular conditions, characterized by a particular variability, is the progress in omics sciences. Shuzhao Li et al., in a recent review of the latest progress in blood transcriptomics and metabolomics, highlighted how these new omics technologies can be the key to fill the gap between genomics and phenotypes. They stressed the role of metabolomics, a fast-growing technology that captures both endogenous metabolites and environmental exposures, for diseases markers. Some examples of metabolomics for biomarker study are presented, such as for diabetes (metabolite markers of diabetes were reported many years prior to the disease onset), nonalcoholic fatty liver disease, asthma, macular degeneration, Parkinson's disease, and tuberculosis. The particularity of metabolomics is that it can match data from other omics technologies allowing the identification and quantitation of specific metabolites. S. Li et al. and K. Beebe and A. D. Kennedy, in their studies, showed how a single blood and/or urine sample submitted for a metabolomics screen can monitor, quickly and at the same time, a multitude of genetic anomalies, suggesting that metabolomics can be considered a potential alternative to clinical blood tests. They, moreover, observed that, with an implementation of metabolomics technology, it could be expected to quantify over 1000 chemicals in less than $10 \mathrm{~min}$, changing at all diagnostic procedures and the clinical practice. Therefore, transcriptomics and metabolomics data from large cohorts can lead to robust models of risk factors and disease mechanisms, helping to better phenotype patients and predict their responses to drugs [53-55].

These finding are well applicable to improve lifestyle. A.A. Vorderstrasse et al. applied this concept in their work showing as the knowledge of risk factors before manifestation of disease can help patient to improve the adherence in several modifications of lifestyle (such as diet, physical activity and smoking cessation) that may reduce individual susceptibility to some condition [52].

Here is the other future possibility of personalized medicine: the personalized lifestyle medicine, a system of medicine that merges technological advances with the traditional foundation of lifestyle through the psychosocial-behavioral interface [56].

The strategy works successfully and is strictly guided by the "precaution principle" which guarantees safe and appro- priate use of genomic data. The workflow is illustrated below in Figs. (1-3).

Statins PGX (up to 19 SNPs)

Thrombophilic and cardiologic risk (up to 15

SNPs)

Anticoagulants PGX (up to 25 SNPs)

AMD risk (up to 15 SNPs)

Hearing loss risk (up to 16 SNPs)

Oxidative stress profile (up to 22 SNPs)

Vitamin B12 absorption (up to 15 SNPs)

Neurological genomics and TDM road map: receptor, metabolism and transporter profiles (up to 35 SNPs)

FELBAMATE, GABAPENTIN, HYDANTOIN, LOSIGAMONE, RUFINAMIDE, STIRIPENTOL, TIAGABINE, ZONISAMINE, VIGABATRIN, LEVETIRACETAM, LAMOTRIGINE,

OXCARBAZEPINE / 10-OH CARBAZEPINE, LACOSAMIDE

\section{Psychiatric metabolomics}

The kynurenine fingerprint

TRYPTOPHAN, KYNURENINE, KYNURENIC ACID, 3-OH

KYNURENINE, XANTHURENIC ACID, ANTHRANILIC ACID, 3-OH

ANTHRANILIC ACID, QUINOLINIC ACID

Functional metabolomics Intestinal permeability evaluation

LACTULOSE-TO-MANNITOL RATIO

SUCRALOSE

SUCROSE

Fig. (1). Clinical applications and principal fields of interest.

\section{PERSONALIZED MEDICINE ISSUES AND HEALTHCARE IMPLICATIONS}

The global impact of personalized medicine is constantly growing in the last years. Charles Auffray et al. (2016) showed the increasing applications of human genetics into public health programs and that numerous initiatives are 


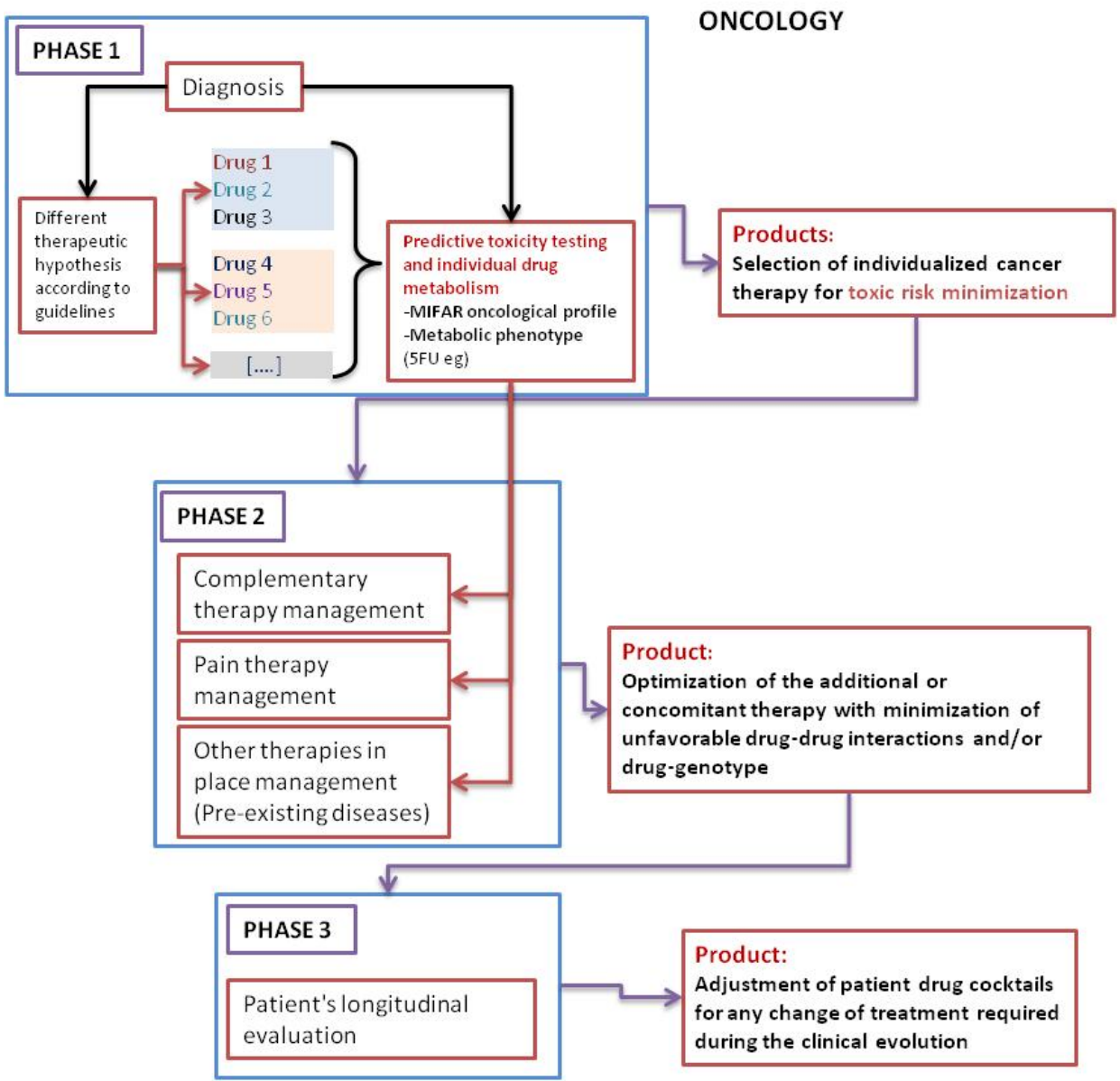

Fig. (2). Workflow in oncology illustrating strategy of safe and appropriate use of genomic data, strictly guided by the "precaution principle".

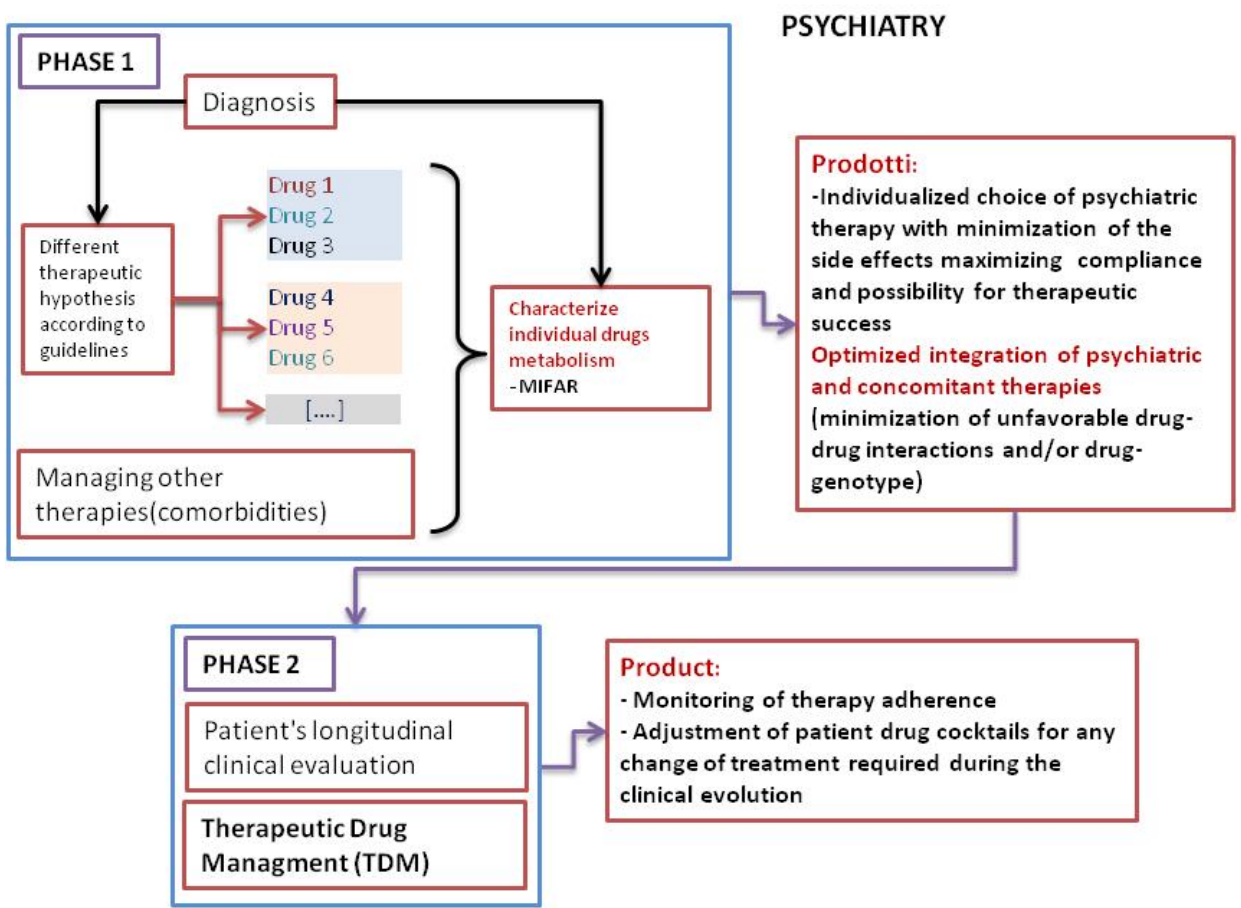

Fig. (3). Workflow in psychiatry illustrating strategy of safe and appropriate use of genomic data, strictly guided by the "precaution principle". 
made around the world to implement clinical genomic, such as the Welcome Trust Deciphering Developmental Disorders (WTDDD) in Europe and the National Human Genome Research Institute Centers for Mendelian Genomics (NHGRI CMG) or The Centers for Disease Control and Prevention (CDC), Advanced Molecular Detection Initiative in USA [57]. As a matter of fact, however, its usage is restricted to a small portion of patients, primarily for the diagnosis of Mendelian conditions and for cancer treatments.

One of the biggest difficulties that, still today, limits the use of PM and, above all, the possibility of even more researches in this field, is the management of the big-data. This issue includes: data storage and processing, data integration and interpretation, generation of cost-effective of big-data and individual and global cost relevance. The main problems that we found include the typical storage of data in a different way in different hospitals and the fact that the electronic health records (EHRs) do not support formats needed to record genetic results. These issues extremely limit the standardization of data, their study and interpretation and then their use. In fact, the great contribution of the collecting genetic information into electronic medical records consists in the possibility to improve the analysis of data as well as to discover the genetic basis of susceptibility to diseases and to drug responses. Therefore, it is necessary to upgrade the collection in data-bank of the amount of data generated by new technologies; this can be possible only by investing more in bioinformatics, biomathematics, and biostatistics [58].

Another big barrier to routine use of PM in clinical care is the lack of different types of trials validating the advantage of using pharmacogenetic in the different fields of application. This prevents the construction of diagnostic and therapeutic algorithms for routinely use.

In the USA, the same President recently announced a Precision Medicine Initiative that aims to accelerate progress toward a new era of PM, with a longitudinal "cohort" of 1 million or more Americans who have volunteered to participate in research. This initiative has two main components: a near-term focus on cancers and a longer-term aim to generate knowledge applicable to the whole range of health and disease [59, 60]. Also, Luxembourg, on May 2015, began an electronic health records project with the cooperation of some 30,000 patients.

Much needs to be done to advance personalized medicine, but many things still have to be defined, especially in Europe. In fact, despite the great strides made in the recent years, in EU there is still a long way to achieve the goals of personalized medicine.

The European Alliance for Personalized Medicine, in fact, highlighted that economic difficulties for health systems in the EU does not mean that patients cannot be helped, and, have to bear the high cost of many new drugs. Pricing and reimbursement of medicines within the EU is a Member State competence and it is the responsibility of the individual Member State to use his bargaining power to reduce costs as low as possible $[61,62]$.

Moreover, a personalized approach to health care may be limited by the lack of knowledge of many clinicians in inter- preting and acting on pharmacogenetic information, as well as by the patient's knowledge and level of autonomy. These barriers must be removedto allow the pharmacogenetic to become a routine part of health care [63].

\section{CONCLUSION}

The challenges of switching from a P4 to a P5 medicine to better protect patients and consumers have two issues with inescapable dimensions, i.e. technological and societal. The first one is evolving, the latter is far more complex [64]. In Europe, discussions are currently taking place to reduce inequalities in access to PM. To this end, there are authors who warned that the advancement of personalized medicine should be based on careful, ethical and responsible research [65]. However, beyond this admittedly important objective, it is a more general problem of the formation of a more mature and conscious scientific culture.

Personalized medicine is therefore proposing a number of social problems that require the development of new processes of collaborating between patients and researchers. It has been pointed out that understanding the public's perceptions, values, and expectations is important given that the public is not only its main beneficiary but also its primary funder [66]. The real game of personalized medicine is therefore played on social comparison, proposing criteria of equity and distribution of resources that need to be carefully evaluated [67]. Education in PM is critical. So the challenge will be critical in order to create projects and strategies in agreemet to the will of the people and attentive to the needs of patients [65].

It is a challenge not easy to win, essential for the optimal course of treatment success: mutual understanding and listening the other's point of view between doctors and patients is needed. Only then, personalized medicine can meet the challenge of being a positive development for future medicine [68].

\section{LIST OF ABBREVIATION}

$\mathrm{PM}=$ Personalized Medicine

\section{CONFLICT OF INTEREST}

The author(s) confirm that this article content has no conflict of interest.

\section{ACKNOWLEDGEMENTS}

Declared none.

\section{AUTHORS' ROLES}

All authors contributed equally to manuscript drafting and critical discussion and approved the final version.

\section{REFERENCES}

[1] Redekop, W.K.; Mladsi, D. The faces of personalized medicine: a framework for understanding its meaning and scope. Value Health, 2013, 16 (6 Suppl), S4-9.

[2] Nicole, S. Personalised medicine: The right treatment for the right person at the right time. Briefing October 2015 European Parliamentary Research Service. http://www.europarl.europa.eu/RegData/etudes/ 
BRIE/2015/569009/EPRS_BRI(2015)569009_EN.pdf (Accessed 23Jul-2016).

[3] National Cancer Institute. Definition of personalized medicine. http://www.cancer.gov/publications/dictionaries/cancerterms?cdrid $=561717$ (Accessed 23-Jul-2016)

[4] Report of the President's Council of Advisors on Science and Technology September 2008. https://search.whitehouse.gov/ search?affiliate=wh\&form_id=usasearch_box\&query=personalized + medicine (Accessed 23-Jul-2016).

[5] Tremblay, J.; Hamet, P. Role of genomics on the path to personalized medicine. Metabolism, 2013, 62(Supp11), S2-5.

[6] Conti, R.; Veenstra, D.L.; Armstrong, K.; Lesko, L.J.; Grosse, S.D. Personalized medicine and genomics: challenges and opportunities in assessing effectiveness, cost-effectiveness, and future research priorities. Med. Decis. Making, 2010, 30(3), 328-40.

[7] Delaney, S.K.; Hultner, M.L.; Jacob, H.J.; Ledbetter, D.H.; McCarthy, J.J.; Ball, M.; Beckman, K.B.; Belmont, J.W.; Bloss, C.S.; Christman, M.F.; Cosgrove, A.; Damiani, S.A.; Danis, T.; Delledonne, M.; Dougherty, M.J.; Dudley, J.T.; Faucett, W.A.; Friedman, J.R.; Haase, D.H.; Hays, T.S.; Heilsberg, S.; Huber, J.; Kaminsky, L.; Ledbetter, N.; Lee, W.H.; Levin, E.; Libiger, O.; Linderman, M.; Love, R.L.; Magnus, D.C.; Martland, A.; McClure, S.L.; Megill, S.E.; Messier, H.; Nussbaum, R.L.; Palaniappan, L.; Patay, B.A.; Popovich, B.W.; Quackenbush, J.; Savant, M.J.; Su, M.M.; Terry, S.F.; Tucker, S.; Wong, W.T.; Green, R.C. Toward clinical genomics in everyday medicine: perspectives and recommendations. Expert Rev. Mol. Diagn., 2016, 16(5), 521-32.

[8] Li, A.; Meyre, D. Jumping on the Train of Personalized Medicine: A Primer for Non-Geneticist Clinicians: Part 3. Clinical Applications in the Personalized Medicine Area. Curr. Psychiatry Rev., 2014, 10(2), 118-132.

[9] Weston, A.D.; Hood, L. Systems biology, proteomics, and the future of health care: Toward predictive, preventative, and personalized medicine. J. Proteome Res., 2004, 3(2), 179-196.

[10] Hood, L.; Friend, S.H. Predictive, personalized, preventive, participatory (P4) cancer medicine. Nat. Rev. Clin. Oncol., 2011, 8(3), 184-187.

[11] Vogt, H.; Hofmann, B.; Getz, L. The new holism: P4 systems medicine and the medicalization of health and life itself. Med. Health Care Philos., 2016, 19(2), 307-23.

[12] Tayo, B.; Teil, M.; Tong, L.; Qin, H.; Khitrov, G.; Zhang, W.; Song, Q.; Gottesman, O.; Zhu, X.; Pereira, A.C.; Cooper, R.S.; Bottinger, E.P. Genetic Background of Patients from a University Medical Center in Manhattan: Implications for Personalized Medicine. PLoS One, 2011, 6(5), e19166.

[13] Mukesh, V. Personalized Medicine and Cancer. J. Pers. Med., 2012, 2(1), 1-14.

[14] National Cancer Institute. Targeted Cancer Therapies Fact Sheet. http://www.cancer.gov/about-cancer/treatment/types/targetedetherapies/targeted-therapies-fact-sheet (Accessed 23-Jul-2016).

[15] Servant, N.; Roméjon, J.; Gestraud, P.; La Rosa, P.; Lucotte, G.; Lair, S.; Bernard, V.; Zeitouni, B.; Coffin, F.; Jules-Clément, G.; Yvon, F.; Lermine, A.; Poullet, P.; Liva, S.; Pook, S.; Popova, T.; Barette, C.; Prud'homme, F.; Dick, J.G.; Kamal, M.; Le Tourneau, C.; Barillot, E.; Hupé, P. Bioinformatics for precision medicine in oncology: principles and application to the SHIVA clinical trial. Front. Genet., 2014, 5, 152 .

[16] Ginsburg, G.S.; Kuderer, N.M. Comparative Effectiveness Research, Genomics-Enabled Personalized Medicine, and Rapid Learning Health Care: A Common Bond. J. Clin. Oncol., 2012, 30(34), 4233-4242.

[17] Ozomaro, U.; Wahlestedt, C.; Nemeroff, C.B. Personalized medicine in psychiatry: problems and promises. BMC Medicine, 2013, 11,132 .

[18] Bragazzi, N.L. Rethinking psychiatry with OMICS science in the age of personalized P5 medicine: ready for psychiatome? Philos. Ethics Humanit. Med., 2013, 8, 4.

[19] Perlis, R.H.; Purcell, S.; Fava, M.; Fagerness, J.; Rush, A.J.; Trivedi, M.H.; Smoller, J.W. Association between treatmentemergent suicidal ideation with citalopram and polymorphisms near cyclic adenosine monophosphate response element binding protein in the STAR*D study. Arch. Gen. Psychiatry, 2007, 64(6), 689-97.

[20] Paddock, S.; Laje, G.; Charney, D.; Rush, A.J.; Wilson, A.F.; Sorant, A.J.; Lipsky, R.; Wisniewski, S.R.; Manji, H.; McMahon, F.J. Association of GRIK4 with outcome of antidepressant treat- ment in the STAR*D cohort. Am. J. Psychiatry, 2007, 164(8), 1181-8.

[21] Clark, S.L.; Adkins, D.E.; van den Oord, E.J. Analysis of efficacy and side effects in CATIE demonstrates drug response subgroups and potential for personalized medicine. Schizophr. Res., 2011 132(2-3), 114-20.

[22] Adkins, D.E.; Souza, R.P.; Aberg, K.; Clark, S.L.; McClay, J.L; Sullivan, P.F.; van den Oord, E.J. Genotype-Based Ancestral Background Consistently Predicts Efficacy and Side Effects across Treatments in CATIE and STAR*D. PLoS One, 2013, 8(2), e55239.

[23] McMahon, F.J.; Buervenich, S.; Charney, D.; Lipsky, R.; Rush, A.J.; Wilson, A.F.; Sorant, A.J.; Papanicolaou, G.J.; Laje, G.; Fava, M.; Trivedi, M.H.; Wisniewski, S.R.; Manji, H. Variation in the gene encoding the serotonin $2 \mathrm{~A}$ receptor is associated with outcome of antidepressant treatment. Am. J. Hum. Genet., 2006, 78(5), $804-14$

[24] Rosenhagen, M.C.; Uhr, M. The clinical impact of ABCB1 polymorphisms on the treatment of psychiatric diseases. Curr. Pharm. Des., 2011, 17(26), 2843-51

[25] Bijl, M.J.; Visser, L.E.; Hofman, A.; Vulto, A.G.; van Gelder, T.; Stricker, B.H.; van Schaik, R.H. Influence of the CYP2D6*4 polymorphism on dose, switching and discontinuation of antidepressants. Br. J. Clin. Pharmacol., 2008, 65(4), 558-64.

[26] McCormack, M.; Alfirevic, A.; Bourgeois, S.; Farrell, J.J.; Kasperavičiūtè, D.; Carrington, M.; Sills, G.J.; Marson, T.; Jia, X.; de Bakker, P.I.; Chinthapalli, K.; Molokhia, M.; Johnson, M.R.; O'Connor, G.D.; Chaila, E.; Alhusaini, S.; Shianna, K.V.; Radtke, R.A.; Heinzen, E.L.; Walley, N.; Pandolfo, M.; Pichler, W.; Park, B.K.; Depondt, C.; Sisodiya, S.M.; Goldstein, D.B.; Deloukas, P.; Delanty, N.; Cavalleri, G.L.; Pirmohamed, M. HLA-A*3101 and carbamazepine-induced hypersensitivity reactions in Europeans. $N$. Engl. J. Med., 2011, 364(12), 1134-43.

[27] Kim, W.J.; Lee, J.H.; Yi, J.; Cho, Y.J.; Heo, K.; Lee, S.H.; Kim, S.W.; Kim, M.K.; Kim, K.H.; In Lee, B.; Lee, M.G. A nonsynonymous variation in MRP2/ABCC2 is associated with neurological adverse drug reactions of carbamazepine in patients with epilepsy. Pharmacogenet. Genomics, 2010, 20(4), 249-56.

[28] Greenbaum, L.; Smith, R.C.; Rigbi, A.; Strous, R.; Teltsh, O.; Kanyas, K.; Korner, M.; Lancet, D.; Ben-Asher, E.; Lerer, B. Further evidence for association of the RGS2 gene with antipsychoticinduced parkinsonism: protective role of a functional polymorphism in the 3'-untranslated region. Pharmacogenomics J., 2009, $9(2), 103-10$

[29] Ruaño, G.; Goethe, J.W.; Caley, C.; Woolley, S.; Holford, T.R.; Kocherla, M.; Windemuth, A.; de Leon, J. Physiogenomic comparison of weight profiles of olanzapine- and risperidone-treated patients. Mol. Psychiatry, 2007, 12(5), 474-82.

[30] McMahon, F.J.; Insel, T.R. Pharmacogenomics and personalized medicine in neuropsychiatry. Neuron, 2012, 74(5), 773-776.

[31] Zhang, L.; Hong, H. Genomic Discoveries and Personalized Medicine in Neurological Diseases. Pharmaceutics, 2015, 7(4), 542-553.

[32] Tan, L.; Jiang, T.; Tan, L.; Yu, J.T. Toward precision medicine in neurological diseases. Ann. Transl. Med., 2016, 4(6), 104.

[33] Lynch, A.I.; Boerwinkle, E.; Davis, B.R.; Ford, C.E.; Eckfeldt, J.H.; Leiendecker-Foster, C.; Arnett, D.K. Pharmacogenetic association of the NPPA T2238C genetic variant with cardiovascular disease outcomes in patients with hypertension. JAMA, 2008 , 299(3), 296-307.

[34] Kamide, K.; Yang, J.; Matayoshi, T.; Takiuchi, S.; Horio, T.; Yoshii, M.; Miwa, Y.; Yasuda, H.; Yoshihara, F.; Nakamura, S.; Nakahama, H.; Miyata, T.; Kawano, Y. Genetic polymorphisms of Ltype calcium channel alpha1C and alpha1D subunit genes are associated with sensitivity to the antihypertensive effects of L-type dihydropyridine calcium-channel blockers. Circ. J., 2009, 73(4), 73240.

[35] Chasman, D.I.; Shiffman, D.; Zee, R.Y.; Louie, J.Z.; Luke, M.M.; Rowland, C.M.; Catanese, J.J.; Buring, J.E.; Devlin, J.J.; Ridker, P.M. Polymorphism in the apolipoprotein(a) gene, plasma lipoprotein(a), cardiovascular disease, and low-dose aspirin therapy. Atherosclerosis, 2009, 203(2), 371-6.

[36] Undas, A.; Brummel, K.; Musial, J.; Mann, K.G.; Szczeklik, A PI(A2) polymorphism of beta(3) integrins is associated with enhanced thrombin generation and impaired antithrombotic action of aspirin at the site of microvascular injury. Circulation, 2001, 104(22), 2666-72. 
[37] Iakoubova, O.A.; Sabatine, M.S.; Rowland, C.M.; Tong, C.H.; Catanese, J.J.; Ranade, K.; Simonsen, K.L.; Kirchgessner, T.G.; Cannon, C.P.; Devlin, J.J.; Braunwald, E. Polymorphism in KIF6 gene and benefit from statins after acute coronary syndromes: results from the PROVE IT-TIMI 22 study. J. Am. Coll. Cardiol., 2008, 5l(4), 449-55

[38] Johnson, J.A.; Zineh, I.; Puckett, B.J.; McGorray, S.P.; Yarandi, H.N.; Pauly, DF. Beta 1-adrenergic receptor polymorphisms and antihypertensive response to metoprolol. Clin. Pharmacol. Ther., 2003, 74(1), 44-52.

[39] Bijl, M.J.; Visser, L.E.; van Schaik, R.H.; Kors, J.A.; Witteman, J.C.; Hofman, A.; Vulto, A.G.; van Gelder, T.; Stricker, BH. Genetic variation in the CYP2D6 gene is associated with a lower heart rate and blood pressure in beta-blocker users. Clin Pharmacol Ther, 2009, 85(1), 45-50.

[40] Simon, T.; Verstuyft, C.; Mary-Krause, M.; Quteineh, L.; Drouet, E.; Méneveau, N.; Steg, P.G.; Ferrières, J.; Danchin, N.; Becquemont, L. Genetic determinants of response to clopidogrel and cardiovascular events. N. Engl. J. Med., 2009, 360(4), 363-75.

[41] Bhatnagar, V.; O'Connor, D.T.; Schork, N.J.; Salem, R.M.; Nievergelt, C.M.; Rana, B.K.; Smith, D.W.; Bakris, G.L.; Middleton, J.P.; Norris, K.C.; Wright, J.T.; Cheek, D.; Hiremath, L.; Contreras, G.; Appel, L.J.; Lipkowitz, M.S. Angiotensin-converting enzyme gene polymorphism predicts the time-course of blood pressure response to angiotensin converting enzyme inhibition in the AASK trial. $J$. Hypertens., 2007, 25(10), 2082-92.

[42] Link, E.; Parish, S.; Armitage, J.; Bowman, L.; Heath, S.; Matsuda, F.; Gut, I.; Lathrop, M.; Collins, R. SLCO1B1 variants and statininduced myopathy--a genomewide study. N. Engl. J. Med., 2008, 359(8), 789-99.

[43] Chasman, D.I.; Posada, D.; Subrahmanyan, L.; Cook, N.R.; Stanton, V.P.; Ridker, P.M. Pharmacogenetic study of statin therapy and cholesterol reduction. JAMA, 2004, 291(23), 2821-7.

[44] Rettie, A.E.; Wienkers, L.C.; Gonzalez, F.J.; Trager, W.F.; Korzekwa, K.R. Impaired (S)-warfarin metabolism catalysed by the R144C allelic variant of CYP2C9. Pharmacogenetics, 1994, 4(1), $39-42$.

[45] Rieder, M.J.; Reiner, A.P.; Gage, B.F.; Nickerson, D.A.; Eby, C.S.; McLeod, H.L.; Blough, D.K.; Thummel, K.E.; Veenstra, D.L. Rettie Effect of VKORC1 haplotypes on transcriptional regulation and warfarin dose. N. Engl. J. Med., 2005, 352(22), 2285-93.

[46] Oldenburg, J.; Müller, C.R.; Rost, S.; Watzka, M.; Bevans, C.G. Comparative genetics of warfarin resistance. Hamostaseologie, 2014, 34(2), 143-59.

[47] Shuldiner, A.R.; Palmer, K.; Pakyz, R.E.; Alestock, T.D.; Maloney, K.A.; O'Neill, C.; Bhatty, S.; Schub, J.; Overby, C.L.; Horenstein, R.B.; Pollin, T.I.; Kelemen, M.D.; Beitelshees, A.L.; Robinson, S.W.; Blitzer, M.G.; McArdle, P.F.; Brown, L.; Jeng, L.J.; Zhao, R.Y.; Ambulos, N.; Vesely, M.R. Implementation Of Pharmacogenetics: The University Of Maryland Personalized Anti-Platelet Pharmacogenetics Program. Am. J. Med. Genet. C. Semin., 2014, 166C(1), 76-84.

[48] Beitelshees, A.L.; Voora, D.; Lewis, J.P. Personalized antiplatelet and anticoagulation therapy: applications and significance of pharmacogenomics. Pharmgenomics Pers. Med., 2015, 8, 43-61.

[49] Pulley, J.M.; Denny, J.C.; Peterson, J.F.; Bernard, G.R.; VnencakJones, C.L.; Ramirez, A.H.; Delaney, J.T.; Bowton, E.; Brothers, K.; Johnson, K.; Crawford, D.C.; Schildcrout, J.; Masys, D.R.; Dilks, H.H.; Wilke, R.A.; Clayton, E.W.; Shultz, E.; Laposata, M.; McPherson, J.; Jirjis, J.N.; Roden, D.M. Operational implementation of prospective genotyping for personalized medicine: The design of the Vanderbilt PREDICT project. Clin. Pharmacol. Ther., 2012, 92(1), 87-95.

[50] Lee, M.S.; Flammer, A.J.; Lerman, L.O.; Lerman, A. Personalized Medicine in Cardiovascular Diseases. Korean Circ. J., 2012, 42(9), 583-591.

[51] Roden, D.M. Personalized medicine to treat arrhythmias. Curr. Opin. Pharmacol., 2014, 15, 61-67.

[52] Vorderstrasse, A.A.; Ginsburg, G.S.; Kraus, W.E.; Maldonado, M.C.; Wolever, R.Q. Health Coaching and Genomics-Potential
Avenues to Elicit Behavior Change in Those at Risk for Chronic Disease: Protocol for Personalized Medicine Effectiveness Study in Air Force Primary Care. Glob. Adv. Health Med., 2013, 2(3), 2638

[53] Li, S.; Todor, A.; Luo, R. Blood transcriptomics and metabolomics for personalized medicine. Comput. Struct. Biotechnol. J., 2016 $14,1-7$.

[54] Beebe, K.; Kennedy, D.A. Sharpening Precision Medicine by a Thorough Interrogation of Metabolic Individuality. Comput. Struct. Biotechnol. J., 2016, 14, 97-105.

[55] Raz, I.; Riddle, M.C.; Rosenstock, J.; Buse, J.B.; Inzucchi, S.E.; Home, P.D.; Del Prato, S.; Ferrannini, E.; Chan, J.C.; Leiter, L.A.; Leroith, D.; Defronzo, R.; Cefalu, W.T. Personalized Management of Hyperglycemia in Type 2 Diabetes Reflections from a Diabetes Care Editors' Expert Forum. Diabetes Care, 2013, 36(6), 17791788

[56] Minich, D.M.; Bland, J.S. Bland Personalized Lifestyle Medicine: Relevance for Nutrition and Lifestyle Recommendations. Scientific WorldJournal, 2013, 129841.

[57] Auffray, C.; Caulfield, T.; Griffin, J.L.; Khoury, M.J.; Lupski, J.R.; Schwab, M. From genomic medicine to precision medicine: highlights of 2015. Genome Med., 2016, 8(1), 12.

[58] Alyass, A.; Turcotte, M.; Meyre, D. From big data analysis to personalized medicine for all: challenges and opportunities. $B M C$ Med. Genomics, 2015, 8, 33.

[59] Collins, F.S.; Varmus, H. A New Initiative on Precision Medicine. N. Engl. J. Med., 2015, 372(9), 793-5.

[60] Khoury, M.J.; Iademarco, M.F.; Riley, W.T. Precision Public Health for the Era of Precision Medicine. Am. J. Prev. Med., 2016 50(3), 398-401.

[61] European Alliance for Personalized Medicine. Conference Report: STEPs in the Right Direction to a Brave New, Healthier \& SMPART Europe. 3rd EAPM Annual Conference 2-3 June 2015. University Foundation, Brussels. http://euapm.eu/pdf/EAPM_Presidency_Conference_Report_Perso nalised_Medicine_Smaller_Members_And_Regions_Together.pdf (Accessed 23-Jul-2016).

[62] European Alliance for Personalized Medicine. A picture paints a thousand words. The state of play in personalized medicine told in cartoons.

http://euapm.eu/pdf/EAPM A picture paints a thousand words The_State_of_Play_in_PM_told_in_Cartoons.pdf (Accessed 23Jul-2016).

[63] Shuldiner, A.R.; Palmer, K.; Pakyz, R.E.; Alestock, T.D.; Maloney, K.A.; O'Neill, C.; Bhatty, S.; Schub, J.; Overby, C.L.; Horenstein, R.B.; Pollin, T.I.; Kelemen, M.D.; Beitelshees, A.L.; Robinson, S.W.; Blitzer, M.G.; McArdle, P.F.; Brown, L.; Jeng, L.J.; Zhao, R.Y.; Ambulos, N.; Vesely, M.R. Implementation of pharmacogenetics: the University of Maryland personalized anti-platelet pharmacogenetics program. Am. J. Med. Genet. C. Semin. Med. Genet., 2014, $166 C(1), 76-84$

[64] Hood, L.; Flores, M. A personal view on systems medicine and the emergence of proactive $\mathrm{P} 4$ medicine: predictive, preventive, personalized and participatory. N. Biotechnol., 2012, 29(6), 613-24.

[65] Budin-Ljøsne, I.; Harris, J.R. Ask not what personalized medicine can do for you--ask what you can do for personalized medicine. Public Health Genomics, 2015, 18(3), 131-8.

[66] Bombard, Y.; Abelson, J.; Simeonov, D.; Gauvin, F.P. Citizens' perspectives on personalized medicine: a qualitative public deliberation study. Eur. J. Hum. Genet., 2013, 21 (11), 1197-201.

[67] Joly, Y.; Saulnier, K.M.; Osien, G.; Knoppers, BM. The ethical framing of personalized medicine. Curr. Opin. Allergy Clin. Immunol., 2014, 14(5), 404-8.

[68] Borro, M.; Simmaco, M.; Aceti, A.; Barni, S.; De Luca, A.; Fineschi, V.; Frati, P.; Girardi, P.; Miozzo, M.; Nati, G.; Nicoletti, F.; Santini, D.; Marchetti, P. H2020 and beyond: skip discrepancy between theory and practice of Personalized Medicine. A position paper by the Italian Society of Personalized Medicine. Curr. Pharm. Biotechnol., 2016, 17(10), 926-9. 